\title{
ИНТЕРПРЕТАЦИЯ ДОХОДА КАК ЭКОНОМИЧЕСКОЙ КАТЕГОРИИ
}

\author{
(c) 2021 Янгирова Елена Ирековна \\ доктор экономических наук, профессор, \\ заведующий кафедрой управления проектами и маркетинга \\ Башкирский государственный университет, Респ. Башкортостан, Уфа \\ E-mail: beglovaelena75@mail.ru \\ (c) 2021 Адылгареев Вадим Ильдусович \\ аспирант кафедры общей экономической теории \\ Башкирский государственный университет, Респ. Башкортостан, Уфа \\ E-mail: adyilgareevvi@mail.ru
}

В статье прослежена трансформация интерпретации дохода как экономической категории в исторической ретроспективе. Выделены основные подходы к трактовке дохода в работах отечественных и зарубежных исследователей, формируемые под влиянием политических, социальноэкономических воззрений существующего строя. Предложена авторская интерпретация дохода.

Ключевые слова: доход, блага, потребление, прибыль, общество, факторы производства, активы

Исследование процессов формирования и распределения доходов населения является достаточно актуальным направлением, поскольку доход - это важнейшая экономическая категория, определяющая степень удовлетворения потребностей индивида. Заметим, что доход существовал на протяжении всей хозяйственной жизни общества до появления самого научного понятия и развития товарно-денежных отношений. В настоящее время интерес к источникам формирования и направлениям распределения доходов в условиях глобализации лишь нарастает. В то же время при всем многообразии работ в современной экономической науке отсутствует единый подход к сущности доходов населения, к трактовке данной категории, определяющей развитие общества.

В настоящее время накопленный научный задел в исследовании доходов населения позволяет трактовать данную дефиницию как средства, полученные индивидом за установленный период времени в результате определенной деятельности. В тоже время данная интерпретация не является единственной и окончательной, так как само понятие «доход» формируется под влиянием источников его образования, которые, в свою очередь, претерпевают изменения в процессе человеческого развития, трансформации роли индивида в современном мире, переосмысления ценностей социума. Так, еще представитель неокейнсианства Дж. Хикс указывал, что с точки зрения экономиста-теоретика «до- ход - очень опасное понятие, которое следует избегать» $[29$, с. 300] и достаточно использовать грубое его определение. Американский экономист Ф.Найт подчеркивал, что «доход предпринимателя имеет явно сложный характер, и связи между составляющими его элементами трудно разглядеть» [17, с. 264].

Следует отметить, что в условиях трансформации хозяйственно-экономической жизни общества определение дохода претерпевает изменения, оставаясь долгое время синонимом понятий «богатство», «благосостояние», «достаток». При этом не все мыслители в своих трудах фокусируются на самом понятии «доход», а акцентируют внимание лишь на его составных частях и на способах образования дохода.

В одном из первых учений о доходах - политическом и экономическом трактате Древней Индии IV-III вв. до н.э. «Артхашастра» («артха» - «учение», «шастра»- «доход» [8, с. 6]) доходы классифицируются в зависимости от источника формирования:

1) от страны (налоги, торговля, пашни, леса, стража, жертвоприношение и т.п.);

2) от крепости (рынок, пошлины, взыскания, ремесленники и т.п.);

3) от рудников (драгоценные камни, полезные ископаемые);

4) от оросительных сооружений (насаждения, цветники);

5) от лесов (ресурсы леса);

6) от пастбищ (животные: козы, буйволы, ко- 
ровы и т.д.);

7) от торговых путей (товары, поставляемые по водным и сухопутным путям).

Кроме того, доходы подразделяются на «текущие, прошедшие и привходящие» [2, с. 66]. Текущий доход поступает ежедневно, прошедший переносится из другой деятельности или местности или образованный ранее, привходящий это доход, который возник из других источников (пожертвования, клады, имущество должников и т.д.).

Древнегреческий мыслитель Ксенофонт приводит ряд практических советов по увеличению доходов государства: покровительство метекам (неполноправным жителям Аттики) за счет расширения их гражданских свобод, политика протекционизма в отношении купцов и судовладельцев, освоение серебряных рудников. Ксенофонт акцентирует внимание на необходимом условии для приумножения дохода - это обеспечение мира как залога развития общества и уменьшения лишних военных трат.

Древнеримский политик Катон Старший, хоть и не отрицал возможность получения дохода посредством торговли или ростовщичества, но отмечал первый способ опасным, а второй противозаконным. «А из земледельцев выходят самые верные люди и самые стойкие солдаты. И доход этот самый чистый, самый верный и вовсе не вызывает зависти, и люди, которые на этом деле заняты, злого не умышляют нисколько» [10, c. 7].

Средневековый богослов Ф.Аквинский считал возможным получение дохода в результате практически любого вида деятельности, так как мир, в котором человек трудится, создан Богом. При этом деятельность не должна быть связана с обманом, наживой при продаже товара дороже его справедливой цены или получением денег за ссуду. Ф.Аквинский хоть и осуждает ростовщичество, но признает возможность получения процента в форме нематериальных благ, например, благодарности или «бескорыстного подарка» [9, с. 43].

В работах поздних меркантелистов (Д.Норс) золото, серебро по своей сути перестают быть мерилом богатством. Материальные и нематериальные предметы рассматриваются с позиции создания дополнительных доходов. «Тот человек богаче, имущество которого находится в состоянии роста, в виде ли сдаваемой в аренду земли, денег ли, приносящих проценты, или то- варов в торговом обороте» [22, с. 36].

Основоположник классической политэкономии в Англии У.Петти доход для рабочего (заработную плату) рассматривал с позиции минимальных средств для существования. «Закон должен был бы обеспечивать рабочему только средства к жизни, потому что если ему позволяют получать вдвое больше, то он работает вдвое меньше» [32, с. 88]. Доходы предпринимателей и землевладельцев У.Петти выразил через ренту, в частности рента земли определялась как разница между стоимостью товара и издержками на его создание, а рента для предпринимателя процент, равный «ренте с такого-то количества земли, которое может быть куплено на те же данные в ссуду деньги» [22, с. 43].

Французский представитель классической политэкономии Р.Кантильон разделял доход в зависимости от деления общества на три класса: наемных рабочих, землевладельцев и предпринимателей. Соответственно, доход для рабочего есть заработная плата, доход для предпринимателя - разница между ценой приобретаемого товара и ценой его продажи, доход для землевладельца - земельная рента. Рента подразделяется на три части: «первую ренту предприниматель-фермер платит земельному собственнику, вторую - городским предпринимателям, покупая их товары, и третью оставляет себе» [22, с. 48].

Глава школы физиократов Ф. Кенэ классифицировал доходы между тремя классами:

1) фермерами-арендаторами или производительным классом, «который возмещает путем обработки территории ежегодные богатства нации, делает затраты на расходы по земледельческим работам и оплачивает ежегодно доходы собственников земли» [12, с. 350];

2) землевладельцами-собственниками или классом собственников, получающим доход (земельную ренту) от производительного класса;

3) ремесленниками и торговцами или бесплодным классом, доход которых формируется за счет первых двух классов.

Основатель классической политической экономии А.Смит в качестве дохода выделяет: заработную плату как результат труда работника; ренту как вознаграждение за пользование земельным участком; прибыль как средства, полученные в результате самостоятельного использования капитала или передачи в качестве ссуды другому лицу. 
Аналогичную точку зрения имели французский экономист Ж.-Б. Сэй и английский экономист Д. Рикардо. Так, Ж.-Б. Сэй дифференцирует три фактора производства и соответствующие им три вида дохода: «труд - заработная плата, капитал - прибыль, земля - рента» [1, с. 306], причем предпринимательский доход - не просто заработная плата, а вознаграждение за способность рационально соединить три фактора производства.

Д.Рикардо подразделяет доход на заработную плату, ренту и прибыль, соответствующий трем классам общества: рабочим, владельцам земли и собственникам денег. Изменение заработной платы не влияет, за исключением некоторых случаев, на изменение цены товара. «Судить о повышении или падении ренты, прибыли и заработной платы можно лишь в соответствии с разделением всего продукта земли [какой-либо фермы] между тремя классами - землевладельцев, капиталистов и рабочих, а не в соответствии со стоимостью этого продукта, определяемого в заведомо изменчивой мере» [13, с. 434].

Согласно К. Марксу, доход «употребляется в двояком смысле: во-первых, для обозначения прибавочной стоимости как продукта, периодически возникающего из капитала, во-вторых, для обозначения части этого продукта, периодически потребляемой капиталистом или присоединяемой им к своему потребительному фонду» [16, с. 596]. В доходе К. Маркс выделяет две части: заработную плату рабочего и доход капиталиста.

Французский экономист, представитель школы маржинализма Л.Вальрас разделяет общественные блага на блага длительного пользования или капитал и блага разового пользования или доходы. Капитал состоит из собственно самого капитала, земли и личных способностей. «Доходы включают в себя прежде всего предметы потребления и сырые материалы, чаще всего вещи материальные, но они включают в себя также - под названием услуг - последовательное использование капиталов, представляющее собой чаще всего вещи нематериальные» [5, с. XVIII].

Основоположник неоклассического направления в экономике А. Маршалл отмечает, что с развитием денежной экономики под доходом часто понимают те поступления, которые получает человек в форме денег, а также вознаграждение, которое получает работник взамен денег. Чистый же доход образуется путем вычета за- трат на производство товара из валового дохода. С общественной точки зрения под доходом А.Маршалл подразумевает «все виды пользы, которую человечество во всякое время извлекает из своих усилий, направляемых в настоящем и направлявшихся в прошлом на то, чтобы заставить природные ресурсы служить ему наилучшим образом» [19, с. 124].

И. Фишер, представитель неоклассического направления, назвал доход «одним из важных видов потока экономических благ» $[23$, с. 8] и определил его как «поток плодов» [23, с. 7], получаемых в течение различного времени от капитала. Капитал же есть богатство или собственность, т.е. поток благ, существующий в данный промежуток времени.

Английский экономист А.Пигу обращает внимание на необходимость определения «минимального уровня дохода». «Его следует понимать не как субъективный минимум удовлетворенности, но как объективный минимум условий» [21, с. 388]. В качестве условий выступают определенные количественные и качественные требования к жилью, еде, медицинским услугам, образованию и т.п. А.Пигу разделяет заработную плату на номинальную и реальную. Реальная заработная плата включает денежные и неденежные поступления, получаемые работником, а также ряд преимуществ, такие как свободный график, близость к дому и т.д.

Дж. Кейнс под доходом понимает «превышение стоимости готовой продукции, проданной в течение известного периода, над непосредственными издержками производства» [11, с. 50]. Дж.Кейнс рассматривает также чистый доход, который образуется путем вычитания из дохода величин издержек использования (издержек потери ценности средств производства) и добавочных издержек (издержек обесценивания средств производства).

Согласно Т.Веблену, основоположнику школы институционализма, тройственную систему факторов производства (капитал, труд и земля), которой соответствуют три источника дохода (прибыль, заработная плата, рента), необходимо дополнить четвертым фактором - предпринимателем, «чей доход, как принято считать, соответствует его созидательному потенциалу в производстве товаров, невзирая на то что все еще остаются некоторые вопросы относительно роли этого предпринимателя в производственной отрасли» [6, с. 24]. 
Представитель неокейнсианства Дж.Хикс различает понятие «доход» с точки зрения разделения экономических процессов на статические и динамические. В статической теории доходом можно считать поступления индивида (заработная плата, рента). В динамической теории доход индивида - «это то, что он может в течение недели потребить и при этом все-таки ожидать, что к концу недели его положение будет таким же, каким было и в начале» [29, с. 295]. При определении общественного реального дохода, по мнению Дж.Хикса, невозможно найти его объективное значение, так как на уровень дохода влияет ожидание цен на потребительские товары. Один из способов произвести подобную оценку - «выразить стоимость действительно существующего к концу данного периода оборудования в ценах, которые могли бы быть назначены на подобное оборудование в начале периода» [29, с. 299]. Накопленный, таким образом, капитал будет реальным капиталом. После этого к полученной величине необходимо прибавить объем потребления в заданный период и скорректировать значение с учетом объема непредвиденных доходов.

Американский экономист, создатель теории монетаризма М.Фридмен доход подразделяет на два вида:

1) перманентный (постоянный) доход - «это доход, ожидаемый потребителями за длительный промежуток времени» [7, с. 295], величина которого зависит от имеющихся средств (фондовых бумаг, недвижимости и т.д.) и человеческого капитала (здоровья, уровня образования, квалификации и т.д.);

2) временный доход - этот доход, который не будет сохранен в будущем.

М.Фридмен определяет доход производителя как разницу между затратами и объемом продаж. Для предпринимателя доход находится в зависимости от того, в каком количестве он владеет тем или иным производственным ресурсом, и цен за использование данного ресурса, установленного рынком. Одним из основных производственных ресурсов являются «личные способности людей, то, что экономисты называют «человеческим капиталом» [28, с. 35]. Работник в своем стремлении получить доход не всегда руководствуется большей заработной платой, одним из факторов выступает также удовлетворенность работой.

П.Самуэльсон и $\quad$ В.Нордхаус определяют доход как «поток зарплаты, процентов, дивидендов и других поступлений, полученных индивидом или страной в течение определенного периода времени (обычно - года)» [26, с. 1316].

Важно отметить, что различия в понятии «доход» нашли отражение и в трудах отечественных ученых.

Так Ю.Крижанич классифицирует доходы на надежные, т.е. приобретенные постепенно и терпеливо в результате труда, и ненадежные, полученные без всяких затрат «либо неправедно, либо жестоким или постыдным способом» [14, с. 380].

Представитель русского меркантилизма А.Ордин-Нащокин основной источник дохода видел в торговых и товарообменных операциях. Прибыль торговца составляла разница между доходом от продажи и величиной пошлины в казну (заранее определенной денежной суммы).

Русский экономист И.Посошков видел рост государственных доходов в обогащении народа. При этом богатство разделял на вещественное и невещественное. Богатство вещественное являлось результатом труда народа как в промышленности, так и в сельском хозяйстве и представляло собой совокупность богатств народа и государства (казны). Под невещественным богатством Посошков подразумевал законы, эффективность управления, правовые нормы и т.д. «Прибыль в понимании И.Т.Посошкова - это разница между ценой и издержками на покупку сырья и содержание рабочих, которая зависит от уровня их оплаты (а не от неэквивалентного обмена, как считали меркантилисты)» [18, с. 3].

Государственные деятели Н.Мордвинов и М.Сперанский основным источником дохода признавали труд, соответственно для повышения доходов необходимо увеличивать производительность труда путем его разделения.

Русский ученый Н. Чернышевский считал, что доход рабочего - его заработная плата «определяется возможностью поддержать существование» [30, с. 22]. С этой точки зрения рабочий практически не отличается от невольного человека с той лишь разницы, что последний получает доход в натуральной форме.

Согласно В.Ленину совокупность заработной платы, прибыли и ренты есть валовый доход. «Чистый же доход есть сверхстоимость» $[15$, c. 45] или прибавочная стоимость, определяется как результат вычитания из валового дохода заработной платы. 
Представитель российского либерализма Б. Бруцкус в противовес марксизму отмечал, что при социализме развитие хозяйства происходит по государственному плану, который построен на данных статистики. И многие категории капитализма утрачивают свое значение. «Между тем никакая рациональная организация хозяйства невозможна без распределения произведенных ценностей на три категории: заработную плату, прибыль и ренту» [4].

Последовательное изучение процессов на трактовку понятия «доход» нашло отражение и в трудах современных отечественных ученыхэкономистов.

Так, в словаре экономических терминов доход интерпретируется в широком смысле как «любой приток денежных средств или получение материальных ценностей, обладающих денежной стоимостью» [24, с. 95] и в узком смысле как прибыль. Доходы подразделяются на:

1) доходы государства (налоги, платежи, поступления в казну и т.д.);

2) доходы фирмы (оплата услуг, проценты от предоставления кредитов, выручка от продажи материальных и нематериальных активов и т.д.);

3) доходы граждан (заработная плата, пенсии, дивиденды, выручка от продажи имущества, интеллектуальной стоимости, стипендии и т.д.).

Также под доходом понимают:

1) сумму денег, полученную за определенное время;

2) «материальные ресурсы, поступающие государству, предприятию, фирме или отдельному лицу в процессе распределения национального дохода» [27, с. 57].

Согласно Г. Вечканову, доход есть «сумма денег, полученная за конкретный период времени в форме заработной платы, жалованья, гонорара, прибыли, ренты, процента, трансфертных платежей (пособия по социальному обеспечению и безработице, социальные пособия многодетным семьям и т.п.)» [7, с. 403].

По мнению М.Абрютиной, доход предприятия на практике измеряется прибылью, причем прибыль есть не только как результат производства, но и распределения.

Г.Журавлева разделяет понятие «доход» с точки зрения налогообложения и экономической теории. В последней доход есть «полученные за определенный период средства, которые могут быть потрачены индивидом без уменьше- ния размеров его богатства» [31, с. 666]. Таким образом, статистикой могут быть не учтены такие виды доходов, как:

1) изменение стоимости акций, которые принадлежат индивиду;

2) дополнительный не денежный доход, например, служебная квартира, бесплатное питание в столовой, служебный автомобиль и т.д.;

3) блага, которые созданы внутри своего хозяйства для потребления;

4) вмененные издержки, которые связаны с собственностью и отсутствием необходимости платить арендную плату.

А. Булатов определяет доходы населения как сумму «денежных средств и материальных благ, полученных или произведенных домашними хозяйствами за определенный промежуток времени» [3].

С точки зрения налогообложения, согласно определению Шанца - Хейга - Саймонса доход рассматривается как увеличение стоимости имущества плюс потребление за определенный период времени («income as an increase in net economic wealth between two points of time, plus consumption during that period» [33, P. 3]).

В статье 41 Налогового кодекса РФ под доходом понимают экономическую выгоду в натуральном или денежном виде, которая учитывается при условии возможности ее оценки и в той мере, в какой можно оценить такую выгоду.

Органы государственной статистики при определении дохода руководствуются Приказом № 465 от 02 июля 2014 г. «Об утверждении методологических положений по расчету показателей денежных доходов и расходов населения». Согласно п. III «Оценка общего объема денежных доходов населения» доходы формируются как совокупность нескольких составляющих:

1) трудовые доходы: доходы лиц, работающих по найму; доходы от самостоятельной занятости;

2) социальные выплаты: пенсии, пособия, социальная помощь, стипендии, страховые возмещения и т.д.;

3) доходы от собственности: депозиты, вклады, доход от ценных бумаг, дивиденды, арендные платежи и т.д.;

4) прочие денежные поступления: выигрыши, переводы, доходы от сдачи вторсырья, доходы в результате незаконной деятельности и т.д.

В целом, вышеуказанные определения дохода зарубежными и отечественными учеными 
Таблица 1. Доход в понимании отечественных и зарубежных мыслителей

\begin{tabular}{|c|c|c|}
\hline Доход & $\begin{array}{l}\text { Отечественные } \\
\text { исследователи }\end{array}$ & $\begin{array}{c}\text { Зарубежные } \\
\text { исследователи }\end{array}$ \\
\hline $\begin{array}{l}\text { - с позиции потребления: количество средств, обеспе- } \\
\text { чивающих необходимый уровень жизни }\end{array}$ & $\begin{array}{l}\text { Н. Чернышевский, } \\
\text { Г. Журавлева }\end{array}$ & У. Петти, А. Пигу \\
\hline $\begin{array}{l}\text { - с позиции поступлений: количество средств, получа- } \\
\text { емых индивидом за определенную деятельность }\end{array}$ & $\begin{array}{l}\text { Б. Бруцкус, Г. Вечка- } \\
\text { нов, А. Булатов }\end{array}$ & $\begin{array}{l}\text { Р. Кантильон, Ф. Кенэ, А. Смит, } \\
\text { Ж.-Б. Сэй, Д. Рикардо }\end{array}$ \\
\hline - разница между объемом поступлений и издержками & $\begin{array}{l}\text { А. Ордин-Нащокин, } \\
\text { И. Посошков }\end{array}$ & А. Маршалл, Дж. Кейнс \\
\hline
\end{tabular}

можно свести к обобщенным интерпретациям, указанным в таблице 1 .

На наш взгляд, в понятие «доходы» следует включать только поступления экономических благ в материальной и нематериальной формах. Под материальной формой понимаются все осязаемые активы, такие как имущество, денежные средства в наличной форме, продукты личного домашнего хозяйства и т.д. Нематериальную форму составляют услуги, электронные переводы, дивиденды, патенты и т.д., т.е. неосязаемые вещи.

Заметим, особенность доходов состоит в необходимости определения и установления их ценности. Например, невозможно обозначить в качестве дохода звездную пыль, воздух или морскую воду. Но в случае возникновения ограничений или прав на использование ресурсов и установления цены данные блага перейдут в область рассмотрения экономических отношений.

Доходам также свойственна территориальная и временная зависимость. Очевидно, что ценность того или иного экономического блага меняется в зависимости от временного периода. Например, денежные средства в современной форме не имели бы такой ценности в эпоху царской России, или участок с залежами нефти не был бы равнозначным предметом аукциона в 17-м и 20-м веках. Следует отметить, что в одном и том же историческом периоде тот или иной доход может восприниматься по-разному, в частности, степень удовлетворенности современного городского человека и представителя африканского племени от приобретения последней модели смартфона различна.

При этом необходимо подчеркнуть, что даже для одного и того же индивида одно и то же экономическое благо представляет различную ценность в разных ситуациях, например, вода для находящегося в пустыне человека имеет большую ценность, чем для того же индивида в современном офисе.

Следовательно, при интерпретации понятия «доход» необходимо учитывать вышеуказанные дополнительные условия. В связи с этим, на наш взгляд, под доходами следует понимать все возможные поступления экономических благ в материальной и нематериальной форме, ценность которых определена и является актуальной для индивида в данном обществе и в конкретный период времени.

Обобщая вышесказанное, можно утверждать, что интерпретации дохода возникали под влиянием политических, социально-экономических воззрений существующего строя и являлись средством для удовлетворения потребностей общества соответствующего периода. Трактовки данной экономической категории в процессе социально-экономического развития отражали путь исторического становления общества, поэтому большая часть из них сегодня утратила свою актуальность. В современном мире в эпоху глобализации доход, являясь важнейшим аспектом жизни человека, требует своего четкого определения с учетом реалий текущей действительности. Приведенная в данном исследовании авторская интерпретация дохода учитывает как наличие новых источников формирования данной категории, так и особенностей его приобретения с учетом временных и территориальных рамок, следовательно, отвечает требованиям современности.

\section{Библиографический список}

1. Аникин А. В. Юность науки. Жизнь и идеи мыслителей-экономистов до Маркса. Изд. 2-е, доп. и переработ.М.: Политиздат, 1975.- 384 с.

2. Артхашастра или наука политики. Перевод с санскрита/ подг. В.И. Кальянов.- Москва, Ленинград: Издательство Академии наук СССР, 1959.- 798 с. 
3. Булатов А. С. Экономика [Электронный ресурс]: электронная библиотека Гумер.- Режим доступа: https:// www.gumer.info/bibliotek_Buks/Econom/economika /28.php [дата обращения 13.03.2021 г.].

4. Бруцкус Б.Д. Социалистическое хозяйство. Теоретические мысли по поводу русского опыта [Электронный peсурс].- Режим доступа: http://ek-lit.narod.ru/brut007.htm [дата обращения 13.03.2021 г.].

5. Вальрас Л. Элементы чистой политической экономии.-М.: Изограф, 2000.-448 с.

6. Веблен Т. Б. Инженеры и ценовая система / пер. с англ. И. Кошкина; под науч. ред. А. Смирнова; Нац. исслед. ун-т «Высшая школа экономики».- М.: Изд. дом Высшей школы экономики, 2018. -112 с.

7. Вечканов Г. С. Экономическая теория: Учебник для вузов. 3-е изд. Стандарт третьего поколения. - СПб.: Питер, 2011.- 512 c.

8. Елисеева Е.Л., Роньшина Н. И. История экономических учений: конспект лекций.- М.: Эксмо, 2008.- 159 с.

9. История экономических учений: учебник для студентов, обучающихся по экономическим специальностям/ под ред. А. Н. Марковой, Ю. К. Федулова. - 2-е изд., перераб. и доп. - М.: ЮНИТИ-ДАНА, 2015. - 471 с.

10. Катон М.П. Земледелие [перев. и коммент. М.Е. Сергеенко].- С.-П.: Наука, 2008. - 221 с.

11. Кейнс Дж. М. Общая теория занятости, процента и денег [вступит. ст. проф. И. Г. Блюмина; пер. с англ. проф. Н. Н. Любимова] - М.: Государственное издательство иностранной литературы, 1948. - 399 с.

12. Кенэ Ф., Тюрго А.Р.Ж., Дюпон де Немур П. С. Физиократы. Избранные экономические произведения/ Ф. Кенэ, А.Р.Ж. Тюрго, П. С.Дюпон де Немур; [предисл. П.Н. Клюкин; пер. с франц., англ., нем.] - М.: Эксмо, 2008.$1200 \mathrm{c}$.

13. Классика экономической мысли: Сочинения.-М.: Изд-во ЭКСМО-Пресс, 2000.- 896 с.

14. Крижанич Ю.Политика [перев. и коммент. А.Л.Гольдберг; под ред. акад. М.Н.Тихомирова].- М.: Наука, 1965.- $736 \mathrm{c}$.

15. Ленин В.И. Полное собрание сочинений. Том 3. Развитие капитализма в России/ В.И.Ленин - «Рublic Domain»,-(Полное собрание сочинений в 55-ти томах). -492 с.

16. Маркс К.Г. Капитал. Критика политической экономии. Том первый. Книга I: процесс производства капитала; Пер. И. И. Степанова - Скворцова - М.: Госполитиздат, 1952.- 794 с.

17. Найт Ф.Х. Риск, неопределенность и прибыль/Пер. с англ.-М.: Дело, 2003. - 360 с.

18. Нечеухина Н. С. Теоретические подходы к формированию и измерению дохода /Нечеухина Н.С., Мустафина О. В. // Международный бухгалтерский учет. - Москва, 2015. - № 31 (373). - с. 2-11.

19. Основы экономической науки/ А. Маршалл; [предисл. Дж. М. Кейнс; пер. с англ. В. И. Бомкина, В. Т. Рысина, Р. И. Столпера] - М.: Эксмо, 2007.- 832 с.

20. Пигу А. Экономическая теория благосостояния, т. І. Пер. с англ.- М.: Прогресс, 1985. -512 с.

21. Пигу А. Экономическая теория благосостояния, т. II. Пер. с англ. - М.: Прогресс, 1985. - 389 с.

22. Покидченко М.Г., Чаплыгина И.Г. История экономических учений: Учеб. пособие.- М.: ИНФРА-М, 2008.$271 \mathrm{c}$.

23. Покупательная сила денег/ И. Фишер; [под ред. и с предисл. проф. В.Я. Железнова; пер. с американского издания К. Г. Фокина] - М.: Финансовое издательство НКФ СССР, 1926.- 402 с.

24. Райзберг Б. А. Словарь современных экономических терминов/ Б. А.Райзберг, Л.Ш. Лозовский. - 4-е изд.М.: Айрис-пресс, 2008.- 480 с.

25. Самуэльсон Пол А. Экономика: Учебник, В сокр. Перевод с англ. - Севастополь: Ахтиар, 1995.- 384 с.

26. Самуэльсон, Пол Э., Нордхаус, Вильям Д. Экономика, 18-е издание; Пер. с англ.- М.: ООО «И.Д. Вильямс», 2007.- $1360 \mathrm{c}$.

27. Словарь-справочник: экономика, внешняя торговля, выставки/авт.-сост. П.А.Кошель; под общ. ред. В. Л. Малькевича. - М.: О-во сохранения лит. наследия, 2012. - 344 с.

28. Фридман М., Фридман Р. Свобода выбирать: Наша позиция/ Пер. с англ. М.: Новое издательство, 2007. - 356 c.

29. Хикс Дж. Р. Стоимость и капитал: Пер. с англ./ Общ. ред. и вступ. ст. Р. М. Энтова - М.: Издательская группа «Прогресс», 1993.- 488 с.

30. Чернышевский Н.Г. Сочинения в 2-х т. Т.2 /АН СССР. Ин-т философии; Редкол.: М. Б. Митин (пред.); Ред. изд. И. К. Пантин; Сост. и авт. примеч. Л. В. Поляков - М.: Мысль, 1987. - 687 с.

31. Экономическая теория. Микроэкономика-1,2: Учебник/ Под общ. ред. заслуженного деятеля науки РФ, проф., д-ра экон. наук Г.П.Журавлевой.- 6-е изд., испр. и доп.- М.: Издательско-торговая корпорация «Дашков и Ко», 2014.- 934 с.

32. Ядгаров Я. С. История экономических учений: Учебник.- 4-е изд., перераб. и доп. -М.: ИНФРА-М, 2009.$480 \mathrm{c}$.

33. Swift Z. Managing the Effects of Tax Expenditures on National Budgets. World Bank Policy Research Working Paper No. 3927. May 2006. P. 3 